\title{
Módulo de Información de Emergencia: Pichilemu
}

\section{FICHA TÉCNICA}

Nombre del proyecto: Módulo de Información de Emergencia en Pichilemu.

Autores: diseño: Stephanie Beaver; construcción: equipo de alumnos Taller Aguilar.

Curso: Taller de Diseño Básico 1 y 2 Escuela de Arquitectura, Universidad de Chile.

Equipo docente: profesor: Rodrigo Aguilar; ayudantes: Sebastián Laclabére + Mique Casassus; monitores: Sebastián Cruz + Diego Hernández.

Ubicación: Pichilemu, VI Región, Chile.

Presupuesto: $\$ 236.000$ (US\$495).

Comunidad beneficiaria: Ilustre Municipalidad de Pichilemu.

\section{MEMORIA}

En el marco del terremoto y posterior tsunami que azotó la zona centro sur de nuestro país el 27 de febrero de 2010, el Taller de Diseño Básico 1 y 2 propone trabajar a través de todo el Primer Semestre del año en el estudio y desarrollo de ejercicios proyectuales asociados a estos fenómenos, en un esfuerzo por acercar el quehacer académico a los problemas contingentes presentes en nuestro contexto social, focalizando las labores en la localidad de Pichilemu.

Desde esta perspectiva, el ejercicio que se presenta a continuación constituye la finalización de un ciclo que abarcó tareas diversas sobre el marco teórico de las catástrofes naturales, el diseño de pequeños equipamientos para hacer frente a la emergencia en poco tiempo y finalmente su concreción a través de la ejecución de un proyecto en cuanto obra de arquitectura.

En el caso particular de Pichilemu, localidad situada en la Región de O’Higgins, el fenómeno aludido afectó principalmente la zona de borde costero. La problemática específica detectada en este caso corresponde a la falta de un acceso rápido y oportuno a información fundamental, que permita prevenir y mitigar en la emergencia, los daños generados por este tipo de desastres naturales.
La propuesta presentada intenta entonces generar un punto de información para los habitantes de Pichilemu. Estas indicaciones incluyen puntos de resguardo, zonas de seguridad, vías de escape y zonas susceptibles de inundación. Además, para los turistas y visitantes ocasionales, se propone la ubicación de información anexa como la localización de carabineros, bomberos, hospitales y otros servicios básicos. Actualmente el área urbana presenta sólo un punto de información emplazado en la municipalidad, pero éste no funciona de manera óptima, pues otorga información de carácter turístico, dificultando el acceso a la información específica anteriormente descrita.

El proyecto busca entonces responder a esta necesidad de información básica y proveer a los usuarios de una fuente oportuna y permanente de advertencia. Para esto se desarrolla un módulo que funcione de manera autónoma, sin necesidad de un trabajador asociado, que pueda disponerse en distintas áreas dentro de la ciudad con el fin de establecer una red de puntos informativos que abarquen toda la zona central de Pichilemu y que pueda otorgar la información necesaria que permita la adecuada prevención frente a situaciones como las sucedidas en el último terremoto. El prototipo además permite su utilización como mobiliario urbano, en un intento de maximizar su uso en tiempos habituales. 

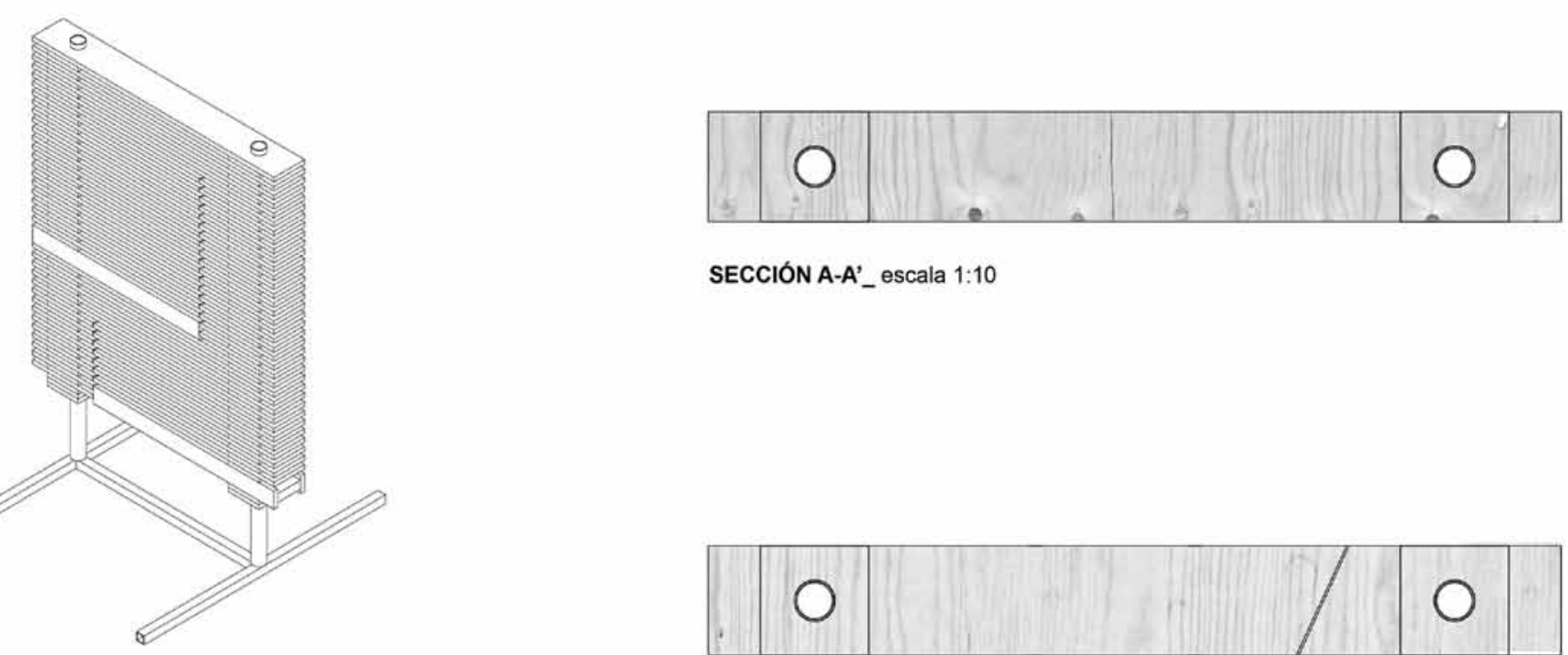

SECCIÓN A-A'_escala 1:10

A través del giro de la sección superior se determina el panel que contendrá la información.
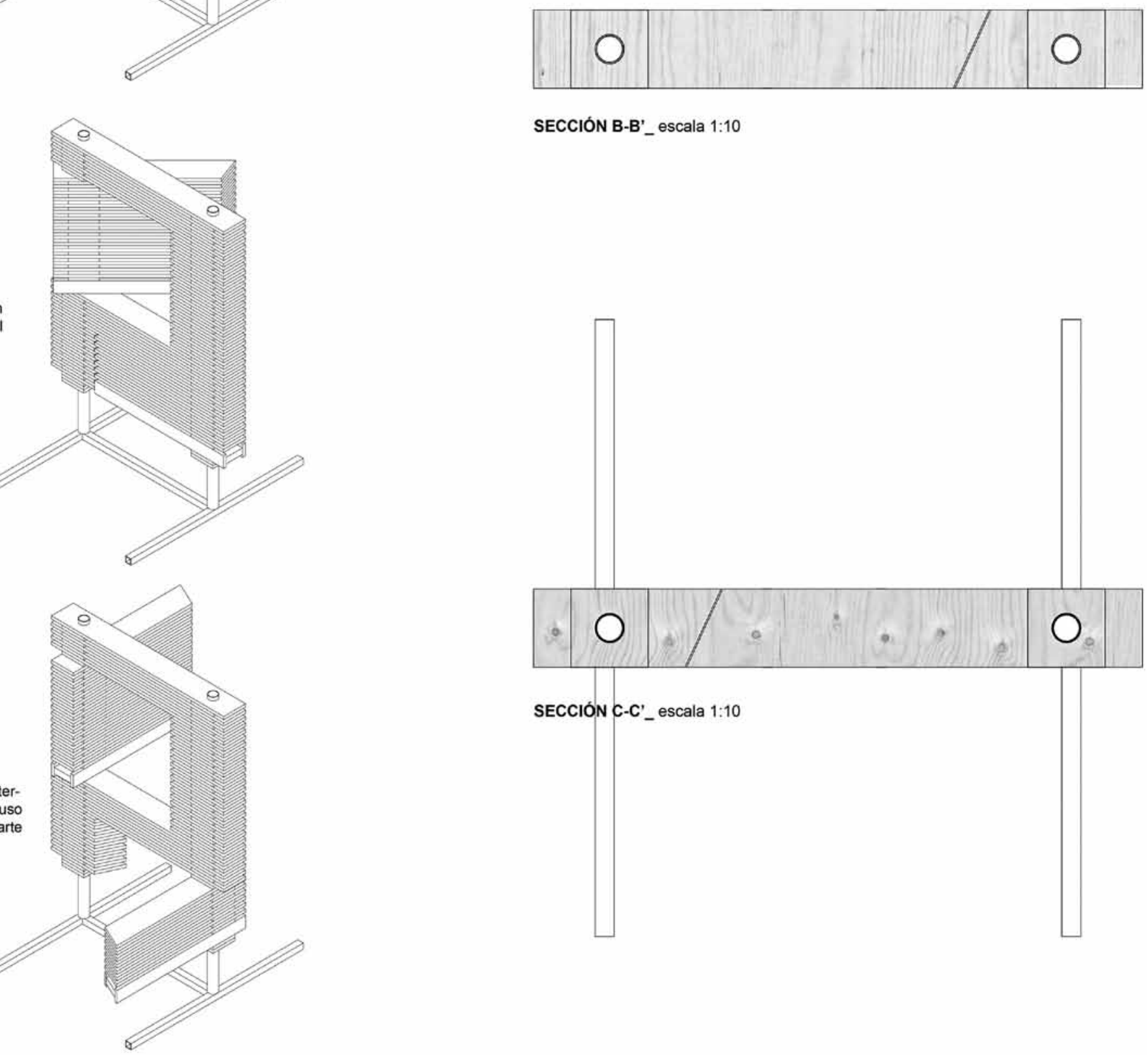

SECCIÓN B-B'_escala 1:10

Al girar la sección inferior se determina una banca que permite el uso del panel como mobiliario por parte de los transeúntes.

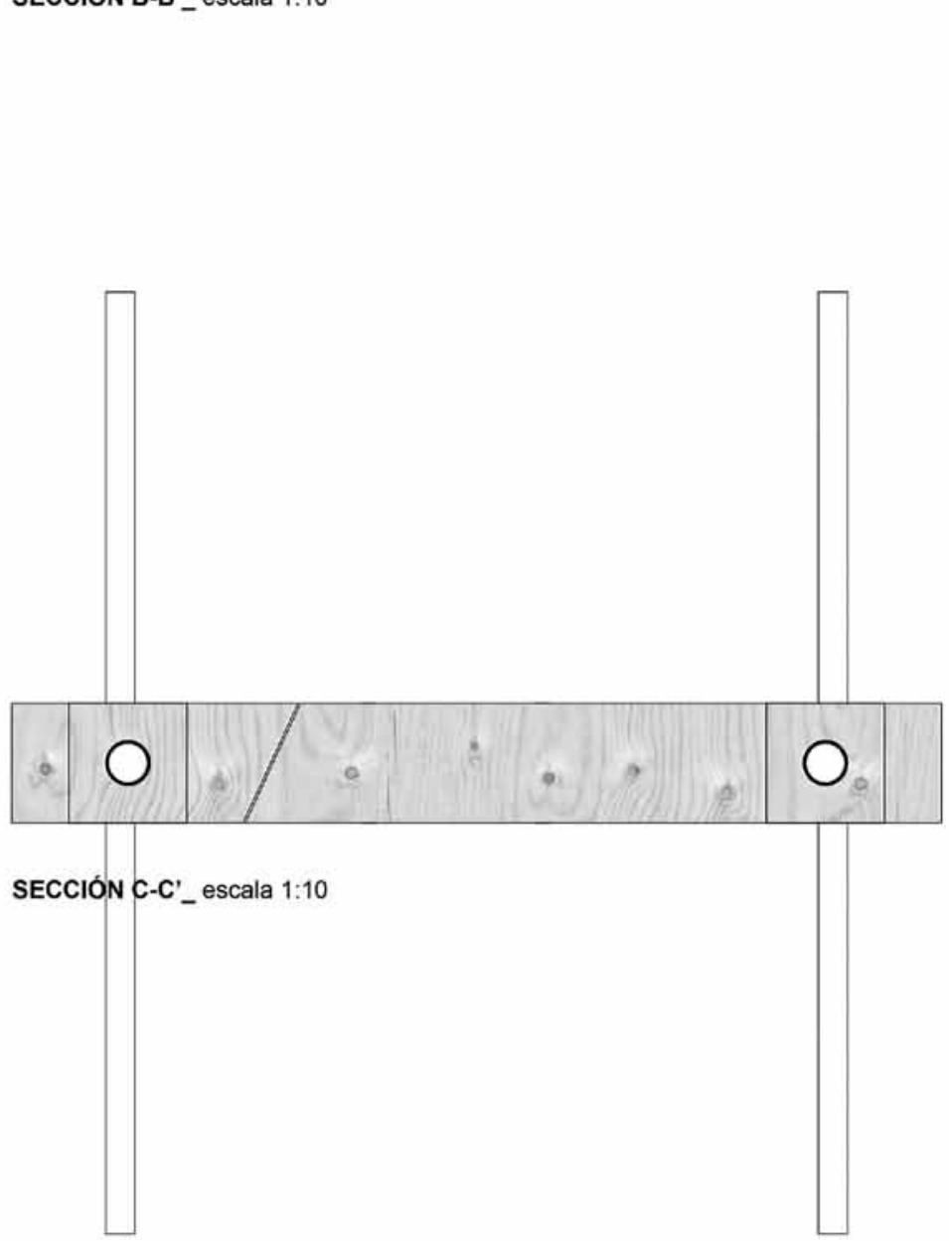

